\title{
The Effect of Economic Insecurity on Mental Health: Recent Evidence from Australian Panel Data ${ }^{1}$
}

\author{
Nicholas Rohde ${ }^{2}$, KK Tang ${ }^{3}$, Lars Osberg ${ }^{4}$ and Prasada Rao ${ }^{5}$
}

\footnotetext{
${ }^{1}$ This paper uses unit record data from the Household, Income and Labour Dynamics in Australia (HILDA) Survey. The HILDA Project was initiated and is funded by the Australian Government Department of Families, Housing, Community Services and Indigenous Affairs (FaHCSIA) and is managed by the Melbourne Institute of Applied Economic and Social Research (Melbourne Institute). The findings and views reported in this paper, however, are those of the author and should not be attributed to either FaHCSIA or the Melbourne Institute. Nicholas Rohde, Kam Ki Tang and Lars Osberg are supported by ARC Discovery Project DP120100204.

${ }^{2}$ Corresponding Author. Dept. Accounting, Finance and Economics, Griffith University, Australia. Email: n.rohde@griffith.edu.au. Ph + 617555 28243. Nicholas Rohde, Kam Ki Tang and Lars Osberg are supported by the ARC Discovery grant DP120100204. Any errors are the authors' responsibility.

${ }^{3}$ School of Economics, University of Queensland, Australia. Email: kk.tang@uq.edu.au.

${ }^{4}$ Dept of Economics, Dalhousie University, Canada. Email: lars.osberg@dal.ca.

${ }^{5}$ School of Economics, University of Queensland, Australia. Email: d.rao@uq.edu.au.
} 


\title{
The Effect of Economic Insecurity on Mental Health: Recent Evidence from Australian Panel Data
}

\begin{abstract}
This paper estimates the impact of economic insecurity on the mental health of Australian adults. Taking microdata from the 2001-2011 HILDA panel survey, we develop a conceptually diverse set of insecurity measures and explore their relationships with the SF-36 mental health index. By using fixed effects models that control for unobservable heterogeneity we produce estimates that correct for endogeneity more thoroughly than previous works. Our results show that exposure to economic risks has small but consistently detrimental mental health effects. The main contribution of the paper however comes from the breadth of risks that are found to be harmful. Job insecurity, financial dissatisfaction, reductions and volatility in income, an inability to meet standard expenditures and a lack of access to emergency funds all adversely affect health. This suggests that the common element of economic insecurity (rather than idiosyncratic phenomena associated with any specific risk) is likely to be hazardous. Our preferred estimates indicate that a standard deviation shock to economic insecurity lowers an individual's mental health score by about 1.4 percentage points. If applied uniformly across the Australian population such a shock would increase the morbidity rate of mental disorders by about $1.7 \%$.
\end{abstract}

\section{Introduction}

Since the widespread financial crisis in 2008 and subsequent global recession, economic insecurity has become a topic of increasing interest to social scientists. This concept refers to the anxiety felt by individuals when they are threatened by the prospect of severe economic losses, and emerging evidence suggests it is a major cause for concern. Survey data routinely shows that financial worries rank amongst the most troubling for households, and related problems have been associated with many social ills including familial breakup (Larson, Wilson \& Beley, 1994), depression (Meltzer et al., 2009; Tsutsumi, Kayaba, Theorell \& Siegrist, 2001), and suicide (Blakely, Collings, \& Atkinson, 2003; Hintikka, Saarinen \& Viinamaki, 1999). The importance of economic security has also been emphasized by Stiglitz, Sen and Fitoussi (2009) who argue that it should be considered as a part of measures of economic performance and social progress; and by the United Nations which declares economic security a universal human right (United Nations, 1948). Further, there is evidence that economic insecurity has been intensifying over recent years (Hacker et al., 2010), a trend which predates the crisis of 2008. Indeed in most developed countries measures of consumer confidence have been declining since the late 1990s, while studies by Hacker (2006), Osberg and Sharpe (2002), Sharpe and Osberg (2009) and Nichols and Rehm (2014) show that this downward trend has been matched by increases in household level economic risk.

This paper models the impact of economic insecurity upon the mental health of Australian adults. There are three primary objectives. The first is to generalize findings from the extant literature on risk exposure and health by showing that negative effects are not limited to one or two specific forms of risk, such as job insecurity or the threat of destitution. Rather there are mental health consequences associated with a wide variety of economic hazards, which 
suggests that the underlying prospect of monetary loss is likely to be an important contributing factor. Secondly the paper addresses a methodological limitation present in some of the previous research in related fields. As both economic insecurity and mental health are likely to be determined by time-invariant individual-specific factors such as genetics and personality; regular statistical estimates that ignore this source of heterogeneity may suffer serious biases. We correct this problem by employing fixed-effects panel data models which can control for these unobservable factors and hence produce better estimates of the underlying relationships. Lastly, the paper aims to quantify the effect that changes in economic insecurity would have on the mental health of the Australian population. By aggregating results over individuals, the paper simulates the effects of economy-wide shocks on the morbidity rates of psychological disorders.

\section{Background}

There exists an extensive body of empirical literature linking health status with certain forms of economic risk exposure. Although individuals face a wide variety of potential hazards, much of this research has focused on the effects of labor market insecurity. Early works by Sverke, Hellgren and Näswall (2002), De Witte (1999), Ferrie et al. (1998), McDonough (2000), Böckerman, Ilmakunnas and Johhansson (2011) and Cheng, Chen, Chen and Chiang (2005) (and many others) have shown that job insecurity is robustly linked to diminished health and wellbeing. More recent studies have expanded this thesis by (i) examining specific aspects of the insecurity/health nexus, and (ii) by employing sophisticated statistical techniques to disentangle causes from effects. Notable works include Green (2011) who links insecurity to broader issues such as happiness and re-employability; Slopen et al. (2012) who consider long-term health effects; and László et al. (2010) and Caroli and Goddard (2013) who examine consequences for heavily protected European workers. Further research by Luechinger, Meieer and Stutzer (2009) shows that job insecurity has broad societal effects while Landsbergis, Grzywacz and LaMontagne (2014) find that insecurity is a significant source of health inequality.

Despite this considerable volume of research, the mechanism underpinning these relationships remains poorly understood. This uncertainty occurs because job losses and other negative economic shocks are often multifaceted phenomena, combining economic (i.e. monetary) disturbances with other social determinants of stress. These social stressors are often hard to quantify, but may be more important than economic losses in their effects upon psychological health. For example an individual with an insecure job faces the potential for lost income, however they also risk a sense of humiliation associated with sacking (Fryer \& Fagan, 2003), feelings of purposelessness due to unemployment (Kessler, Turner \& House, 1989) and social isolation from former colleagues (Lim, 1996). Similarly mortgage foreclosure is known to deteriorate health (Cannuscio et al., 2012) which may be due to financial strain, or to coincidental factors such as the stress of home relocation (Raviv, Keinan, Abazon \& Raviv, 1990). As social/contextual stressors such as these frequently occur simultaneously alongside economic shocks, it is difficult to identify which are the true sources of mental strain. Indeed it is possible that the threat of economic loss is relatively benign for health, and that it is the confounding presence of these other factors that have driven the results found in the empirical literature.

Determining which components of economic risk exposure are harmful for mental health is important from an epidemiological point of view, and for the formulation of policy. If it is the prospect of economic hardship that is damaging, then threats to income or wealth will have widespread effects upon population health, as virtually all individuals will face some 
exposure to these types of risk. In this instance policies that protect against economic losses such as stronger labor market regulations and more extensive social safety nets could be expected to be beneficial. Conversely, if it is the social or non-monetary aspects of risk exposure that are damaging, this suggests a subtler and more complicated relationship between economic stability and health. Such a finding would require a reinterpretation of the risk/health literature and would imply that social insurance mechanisms may be ineffective in buttressing psychological wellbeing. In this case further research into the specific idiosyncratic causes would be needed such that health-orientated policies could be appropriately targeted.

The main goal of this paper is to determine the roles that the economic aspects of risk exposure play in determining health. This requires measuring economic insecurity, which has typically presented a challenge to social scientists as the contribution of economic risk to an individual's sense of stress is inherently unobservable. However the concept can be operationalized by measuring specific phenomena that are likely to be stressful and combining these indicators with the aim of inferring the resultant sense of anxiety. Economic insecurity is thus seen as a multidimensional concept that includes (alongside job insecurity) the risk of poverty (Bandyopadhyay \& Cowell, 2007; Calvo \& Dercon, 2005), income volatility (Barnes \& Smith, 2009; Smith, Stoddard \& Barnes, 2011; Rohde, Tang \& Rao, 2014), bankruptcy (Kalleberg, 2009), loss through family dissolution, crime or widowhood (Western, Bloom, Sosnaud \& Tach 2013; Osberg \& Sharpe, 2002), wealth dynamics (Bossert \& D'Ambrosio, 2013; D'Ambrosio \& Rohde, 2014) and lack of access to insurance, in particular health insurance (Dominitz \& Manksi, 1997; Bucks, 2011; Hacker, 2006; Hacker et al., 2010). At the aggregate level phenomena such as business cycles (Stuckler et al., 2011) and exposure to international competition (Scheve \& Slaughter, 2004; Standing, 1997) are also relevant.

While this multifaceted approach cannot explicitly identify the aspects of risk exposure that damage mental health, it does provide scope for narrowing the field of candidate explanations. The economic, or monetary explanation predicts that all risks that have an individual or household-level financial element should have adverse health implications. Conversely the incidental, or non-monetary explanation predicts that only risks that also provoke negative social responses should be harmful. We may therefore gain an appreciation as to how important the economic aspects are by searching for consistency in effects across differing forms of risk exposure. If a large and diverse set of economic risks is found to exert negative impacts (especially if these impacts are of similar magnitudes) this would suggest that the common monetary element plays a fundamental role. However if only some economic risks are harmful, and if there is a large degree of variation in the way that health responds to differing risks, this would suggest that there were other risk-specific phenomena besides monetary risk that are more important. Of course there are limitations with such an approach as it is possible that both monetary and non-monetary factors could measurably influence health; that there are non-monetary effects associated with all hazards; or that individuals have differing sensitivities to alternative types of monetary risk. Nonetheless in the absence of quantitative data on the multitude of social dimensions of economic stress, such a method can take a step towards clarifying this important issue.

\section{Methods}

\section{Data}


This study uses Australian HILDA (Household Income and Labour Dynamics in Australia) panel data, which has followed almost 20,000 individuals annually from 2001 to 2011. This data set is unusually rich in questions on health outcomes (particularly mental health) and economic risk. Our focus on Australia provides a useful complement to the US, UK or European locus of most of the existing research on economic insecurity and health, enabling us to extend this literature to another developed country with a different social welfare system, cultural norms and attitudes to risk. As well, we are able to examine various facets of risk in more detail than we could with other countries data sets.

We take health data from the SF-36 survey which is a widely used generic multi-item health assessment tool (Bowling, 1997). The variable is obtained from 36 questions relating to eight different facets of physical and mental health where the responses are aggregated to give each individual a score from 0 to 100 such that higher scores indicate better health perceptions. The SF-36 is often partitioned into a physical functioning variable and a mental health variable, both of which operate in the same manner as the overall SF-36. We use the mental health index which quantifies respondent vitality, social functioning, emotional functioning and anxiety/depressive symptoms. The index is routinely modeled as a continuous variable and is taken in every wave in the HILDA survey.

In addition to the mental health indicator a number of other variables are taken to measure economic insecurity. These include standard variables such as employment status and income, but we also use subjective questions on financial satisfaction, feelings of job insecurity, and the perceived ability of householders to raise emergency funds. Dichotomous variables that indicate whether or not individuals could meet standard expenses such as rental repayments or utility bills are also employed. Further, a number of variables that may be associated with mental health are taken as controls. Data on age, education, household size, marital status, and geographical location all serve to account for extraneous determinants of mental health. Household income is measured in "disposable" terms using 2011 Australian dollars and is standardized by the square root of the household size, while education is measured by a series of dummies indicating various levels of attainment. We also use dummy variables to control for the impact of important life events occurring in the previous 12 months including marriages, separations, pregnancies, births, deaths of family members and victimhood of physical violence. In total the range of control variables is large and captures most of the social drivers of stress or anxiety (Mirowsky \& Ross, 1989). Although all data are drawn from the HILDA survey the more sensitive information (mental health scores, subjective personal assessments on insecurity and occurrences of major life events) comes from the self-completed section while the remaining variables are obtained via interview. As with all large panel surveys our data contain many missing values which could adversely affect the analysis. However we ran simulations using multiple imputation techniques and found that results are generally unaffected by this phenomena (see appendix A1).

The following notation is used throughout the paper. Our mental health index is denoted with the matrix $M$ such that $M_{i t}$ refers to the score of the $i$ th individual in period . J insecurity measures are used and these are $E I^{1}, E I^{2}, \ldots, E I^{J}$ where $E I_{i t}^{j}$ has the same interpretation as above. Control variables are contained in vector $X_{i t}^{\prime}$, while income, being a variable of particular interest as it is used to obtain certain insecurity measures, is denoted with the vector $\tilde{x}_{t}$.

\section{Measuring Economic Insecurity}

To measure economic insecurity we employ a basket of proxy indicators designed to capture differing aspects of risk exposure. Conceptual diversity between the measures is paramount 
here, as we wish to ensure that our results are not being driven by some confounding factor that is specific to a particular type of risk or measurement concept. To avoid problems associated with multiple testing (Gelman \& Loken, 2013) we select indices that either have a precedent in the literature (such as the probability of unemployment) or a strong intuitive connection with the economic risks that individuals typically face.

In order to quantify insecurity appropriately it is necessary to consider some desirable properties for an index to exhibit. Ideally a measure should (i) reflect some potentially stressful economic risk, (ii) be prospective rather than retrospective, and (iii) be personal, meaning that it is sensitive to individual differences in temperament and attitudes to risk (Osberg, 1998). Practically it can be difficult to produce measures that satisfy these criteria, with only subjective surveys of individual level economic perceptions reliably meeting all three. Despite this, there are also roles for objective measures of economic risk which are less personal but more easily interpretable. Objective measures that have been employed in the literature have tended to either focus explicitly on the instability of income, or measure the probability of some hazardous event such as unemployment occurring. This paper uses all three types of measures (subjective surveys, income instability measures and probabilistic hazard indices) and we provide details of each in the following sections.

\section{Subjective Indicators}

The three subjective questions in the data set capture important, but slightly different aspects of economic insecurity. The first question asks the individual to evaluate their feelings of security in their main form of employment - clearly the possible loss of current labour income is hugely important for almost all family budgets. However, other risks may also matter for specific households and the second question asks for an all-things-considered overall level of financial satisfaction. Finally, the anxiety felt by individuals may also depend on their ability to ride out a bad economic period, so a third measure asks respondents how easily they could raise emergency funds if needed. Although all the variables are ordinal each is interpreted with a linear scale - inverted when appropriate such that higher scores imply greater risk. The measures are denoted

$$
\begin{aligned}
& E I_{i t}^{1}=8-J S_{i t} \\
& E I_{i t}^{2}=10-F S_{i t} \\
& E I_{i t}^{3}=E F
\end{aligned}
$$

where $E I_{i t}^{1} \in\{0,1,2, \ldots, 8\}, E I_{i t}^{2} \in\{0,1,2, \ldots, 10\}$, and $E I_{i t}^{3} \in\{1,2, \ldots, 4\}$ measure $j o b$ insecurity, financial dissatisfaction and ability to raise emergency funds respectively; and $J S$, $F S$ and $E F$ are the variables from the HILDA data set.

\section{Income Stream Indicators}

In addition to the subjective questionnaire variables we use two objective indicators based on income streams. Income based indicators typically measure negative instability and have been used as a basis for measurement by Hacker et al. (2010), Rohde et al. (2014) and Nichols and Rehm (2014). The central idea is that volatility, and in particular downward movements, will highlight an unreliable income and therefore capture an important aspect of insecurity. We employ a dichotomous variable that takes on a value of 1 for all individuals within a household if their income (i) drops more than $25 \%$ from the previous period, and (ii) is lower than their average income over the 11 waves. This income drop variable relies upon being a predictor of future distress for prospective relevance and is given as 


$$
E I_{i t}^{4}=\left\{\begin{array}{l}
1 \text { if } \tilde{x}_{i t}<0.75 \times \tilde{x}_{i t-1} \text { and } \tilde{x}_{i t}<1 / T \sum \tilde{x}_{i t} \\
0 \text { otherwise }
\end{array}\right.
$$

A second measure based on income dynamics is a level-and-change $(L \& C)$ index inspired by the prominent work of Bossert and D'Ambrosio (2013), who are the first authors to provide a solid axiomatic foundation for economic insecurity. Their method is based upon household wealth streams however as wealth is not a regular feature of our data we apply their ideas to income instead. In this instance the index treats insecurity as a function of current income and a weighted sum of the differences between lags $\tilde{x}_{i t-1}, \tilde{x}_{i t-2}, \ldots, \tilde{x}_{i 1}$ and combines these two components with a time discounted weighting function that emphasizes the recent over the distant past. An asymmetric weight is also used to emphasize downward movements in line with the theory of loss aversion of Kahneman and Tversky (1979). The index can be written as

$$
E I_{i t}^{5}=-\tilde{x}_{i t}+\sum_{l=1}^{L} \alpha(l) \Delta_{l}\left(\tilde{x}_{i t}\right)+\sum_{l=1}^{L} \beta(l) \Delta_{l}\left(\tilde{x}_{i t}\right)
$$

where $\Delta_{1}\left(\tilde{x}_{i t}\right)=\left(\tilde{x}_{i t}-\tilde{x}_{i t-1}\right), \Delta_{2}\left(\tilde{x}_{i t}\right)=\left(\tilde{x}_{i t-1}-\tilde{x}_{i t-2}\right)$ etc, $l=1 \ldots L$ is the lag length and set equal to a maximum value of three, and

$$
\alpha(l)=\left\{\begin{array}{ll}
\gamma /(2 l-1) & \text { if } \Delta_{1}\left(\tilde{x}_{t}\right)<0 \\
0 & \text { if } \Delta_{1}\left(\tilde{x}_{t}\right)>0
\end{array} \text { and } \beta(l)= \begin{cases}\alpha(l) / 2 & \text { if } \Delta_{1}\left(\tilde{x}_{t}\right)>0 \\
0 & \text { if } \Delta_{1}\left(\tilde{x}_{t}\right)<0\end{cases}\right.
$$

where $\alpha(l)$ and $\beta(l)$ come from the inverse Gini social evaluation functions given in Donaldson and Weymark (1980). Lastly $\gamma>0$ is a parameter that weights between levels and changes, and a fixed $\gamma=5$ is used to emphasis the change component. The index is homogeneous of degree one in income and has support on $\mathbb{R}$ where higher values indicate greater insecurity.

\section{Probability Indicators}

To complete the basket, three probabilistic measures are employed based on the chance that an individual will experience an adverse financial event in the coming year. Let y it be a generic dichotomous indicator of (i) unemployment for the individual at the time of the survey, and (ii) experiencing an income drop of the type defined in $\mathrm{Eq}$ (4). A prospective measure is then the probability of either event occurring in the next wave of the data based upon the data available to the individual in the current period. To model this we take a probit specification and produce forecasts for these hazards occurring. The indices are then $E I_{i t}^{6} \in$ $[0,1]=\hat{y}_{i t+1}$ where $\hat{y}_{i t+1}$ is determined on the basis of unemployment and $E I_{i t}^{7} \in[0,1]=$ $\hat{y}_{i t+1}$ when $\hat{y}_{i t+1}$ comes from the income drop variable $E I_{i t}^{4}$. The measures therefore give respectively the predicted probability of unemployment next year and the predicted probability of an income drop of the type defined in Eq (4).

The same idea is used to construct a measure of distress based upon other sources of financial strain such as the inability to meet standard expenses. We use dummy variables to indicate (i) an inability to pay utility bills (electricity, gas, telephone), (ii) a failure to make a rental or mortgage payment, (iii) pawning or selling household items and (iv) going without meals. The dummy variables are aggregated and an ordered probit then forecasts the probability that an individual will exhibit signs of expenditure related stress in the forthcoming year. This last measure is denoted $E I_{i t}^{8} \in[0,1]$. 
The above basket of indicators considers a variety of aspects of economic insecurity. Our conception of economic insecurity as the anxiety felt by individuals when they are threatened by the prospect of severe economic losses is inherently a latent phenomenon which can only be observed indirectly. Therefore a priori it is unknown how well each measure serves the intended purposes. However our hypothesis that the measures are all quantifying different aspects of the same underlying issue can be checked by searching for consistency across the range of indicators. A brief analysis (not shown) indicates that in all 28 pairwise cases the indices are positively correlated, while empirical copula densities indicate high concentrations of individuals exist in both tails of bivariate insecurity distributions. Thus it appears that the measures are all appropriately related which reinforces the notion that they pick up somewhat differing aspects of the same underlying issue.

\section{Model Specification and Results}

The purpose of the paper is to model the relationships between each $E I^{1}, E I^{2}, \ldots, E I^{J}$ and $M$, and to look for similarities/differences across these relationships. Initially however it is useful to examine the raw associations to gain an appreciation of the size of the underlying dependencies. All eight measures coincide with diminished mental health while Figure 1 shows kernel regressions of mental health against the insecurity measures. As the indices are distributed differently with diverse units of measurement, each is transformed by mean differencing and dividing through by the standard deviation. This gives each index a standard-deviations-from-mean interpretation denoted $\Phi$. Gaussian kernel regressions are used to extract the underlying dependencies.

Figure 1: Within-Individual Variation of Mental Health Scores with Economic Risk Indicators
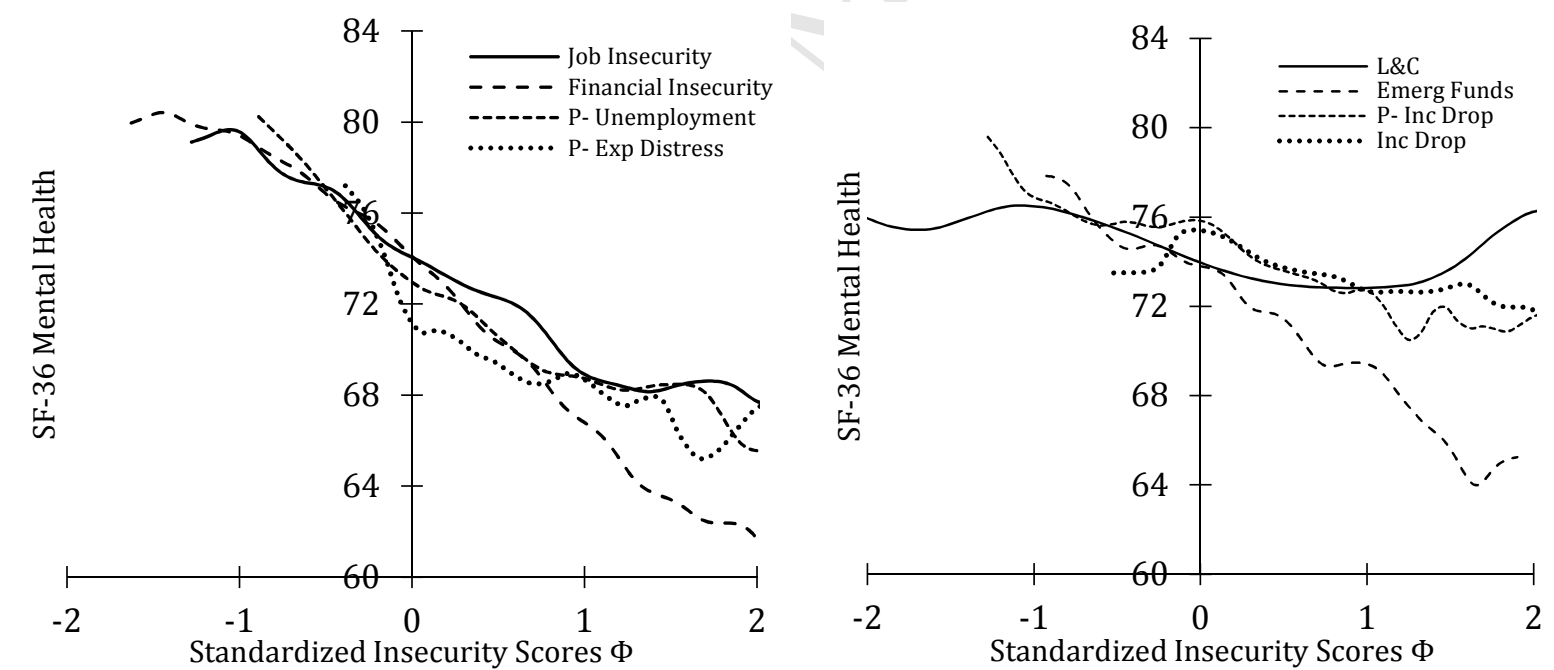

Note: The horizontal axes give the insecurity measures defined in terms of standard deviations from the mean while the vertical axes give the SF-36 Mental Health summary index. All estimates are based upon betweenindividual variation taken over the full 11 year panel.

Figure 1 illustrates the negative associations between each measure and individual mental health. Both sets of curves indicate that psychological health is disproportionately lower in persons who are economically insecure. Comparing the separate regressions shows a degree of unanimity between the results which suggests psychological wellbeing is approximately equally sensitive to the different dimensions. These lines have fairly constant average slopes from -2 to -4 units per standard deviation, a figure which also corresponds to 2-4 percentage points of its maximum value. An exception is the $\mathrm{L} \& \mathrm{C}$ index which shows only a vague negative association with mental health. 
Another way to characterize the raw associations between insecurity and health is to use intertemporal variability to identify persons who had scores that increased or decreased by some margin over a year long period, and examine changes in their mental health scores. Table 1 shows the percentage of persons who had their insecurity scores increase or decrease by more than a single (cross sectional) standard deviation and the corresponding differential in mental health. The first two rows show that changes of this magnitude affected $3 \%$ to $13 \%$ of individuals in a given year depending on the choice of measure. The third row indicates that persons who saw their insecurity levels increase had much lower health scores over all measures. Surprisingly persons who had large decreases in insecurity tended to also have poorer mental health, although the result is more ambiguous and depends upon the measure under consideration. This makes sense however if we consider that a rapid improvement in economic safety is likely to be driven by other forms of personal change (such as taking on a high paying job) which may also yield short term stress and therefore temporarily damage mental wellbeing.

Table 1:Intertemporal Changes in Insecurity and Mental Health

\begin{tabular}{|c|c|c|c|c|c|c|c|c||}
\hline \multicolumn{70}{|c|}{ Insecurity Measures } \\
\hline Changes & $E I^{1}$ & $E I^{2}$ & $E I^{3}$ & $E I^{4}$ & $E I^{5}$ & $E I^{6}$ & $E I^{7}$ & $E I^{8}$ \\
\hline \hline$\% \Delta \uparrow$ & $12.57 \%$ & $7.93 \%$ & $3.15 \%$ & $4.20 \%$ & $10.92 \%$ & $3.01 \%$ & $4.96 \%$ & $3.06 \%$ \\
\hline \hline$\% \Delta \downarrow$ & $13.69 \%$ & $9.06 \%$ & $4.23 \%$ & $3.67 \%$ & $11.11 \%$ & $4.66 \%$ & $8.76 \%$ & $3.66 \%$ \\
\hline \hline$\Delta \bar{M} \uparrow$ & -1.422 & -1.727 & -1.729 & -0.084 & -0.280 & -1.247 & -0.335 & -0.858 \\
\hline \hline$\Delta \bar{M} \downarrow$ & 1.201 & -1.974 & -2.568 & -0.786 & 1.427 & -1.457 & 0.671 & -4.308 \\
\hline
\end{tabular}

Note: The first row gives the percentage of individuals who experienced at least a one standard deviation increase in insecurity over a 12 month period, and the second row gives the percentage who experienced the corresponding decrease in insecurity. The third and fourth columns give the average difference in mental health scores for these persons relative to the sample average.

Given the associations outlined in Figure 1 and Table 1, our task is to estimate the relationships while controlling for extraneous factors, including (i) individual-specific heterogeneity, (ii) major changes in life circumstances, and (iii) current levels of material wellbeing. Throughout the paper the Fixed Effects (FE) model is used

$$
M_{i t}=\alpha_{i}+\gamma_{t}+X_{i t}^{\prime} \beta+\phi^{j} E I_{i t}^{j}+\varepsilon_{i t}
$$

where $\alpha$ is an $n \times 1$ dimensional vector of individual effects, $\beta$ is a $k \times 1$ dimensional vector of parameter estimates, $\phi^{j}$ is a scalar coefficient on $E I_{i t}^{j}, \gamma_{t}$ is a series of annual dummies and $\varepsilon_{i t}$ is an error term. While it would be possible that $\alpha$ may be uncorrelated with $X$ (and hence a Random Effects (RE) model may be applied) on the basis of endogeneity tests (Hausman, 1978) we will only report results from FE estimates. These have the benefit of controlling for all time-invariant factors and therefore do not suffer from many of the endogeneity problems that plague most econometric models. Our models use longitudinal variation over the full eleven waves and parameters are estimated by OLS. To account for potential heteroskedasticity and idiosyncratic effects we use cluster-robust standard errors 
throughout. In some instances there are missing values which makes our panels unbalanced, and therefore a Missing at Random assumption is required. Due to the emphasis on intertemporal variation singleton observations are dropped.

For the sake of robustness four versions of the model given in Eq (6) are employed. Model (1) uses no time varying controls and simply regresses the mental health outcome on the individual specific effect $\alpha_{i}$ and year fixed effects $\gamma_{t}$. Model (2) adds a standard set of controls that may plausibly affect mental health such as logged income, household size, current employment status, educational attainment dummies (less than high school, high school, diploma, bachelor's degree, advanced degree) marital status (married, single, separated, divorced, widowed) and dummies for state of residence and for living in a capital city. Model (3) uses dummies indicating major life events as controls (births, deaths, pregnancies, marriages etc) while Model (4) employs all available controls. The results are given in the leftmost columns of Table 2 where we report estimates of the key parameter $\hat{\phi}$ for each insecurity measure.

Table 2:Estimated Impacts of Economic Insecurity on SF-36 Mental Health

\begin{tabular}{|c|c|c|c|c|c|c|c|c|}
\hline Variable & & Unit Char & $\operatorname{nges}(\hat{\phi})$ & & & Std Dev $S$ & Shocks $(\hat{\theta})$ & \\
\hline & (1) & (2) & (3) & (4) & (1) & (2) & (3) & (4) \\
\hline Job Insecurity - $E I^{1}$ & $-0.754 * * *$ & -0.735 **** & -0.767 **** & $-0.756^{* * * * * *}$ & $-1.281 * * *$ & $-1.249 * * *$ & $-1.302 * * *$ & $-1.283^{* * * *}$ \\
\hline Financial Diss $-E I^{2}$ & $-0.856 * * *$ & $-0.826 * * *$ & $-0.846 * * *$ & $-0.828 * * *$ & $-1.968 * * *$ & $-1.899 * * *$ & $-1.945 * * *$ & $-1.904 * * *$ \\
\hline Emerg Funds - $E I^{3}$ & $-1.303 * * *$ & $-1.232^{* * * * *}$ & $-1.270^{\text {**** }}$ & $-1.230 * * * *$ & $-1.384 * * *$ & $-1.307 * * *$ & $-1.348 * * *$ & $-1.306^{* * *}$ \\
\hline Income Drop - $E I^{4}$ & $-0.667 * * *$ & -0.217 & $-0.566^{* * *}$ & -0.159 & $-0.181 * * *$ & -0.059 & $-0.154 * *$ & -0.043 \\
\hline L\&C Index $-E I^{5}$ & $-1.1 \mathrm{E}-6 * * *$ & $4.6 \mathrm{E}-7$ & $-9.1-07 * *$ & $5.8-07$ & $-0.106^{* * * *}$ & 0.044 & $-0.085 * *$ & 0.055 \\
\hline $\mathrm{P}$ - Unemploy - $E I^{6}$ & $-35.87 * * *$ & $-49.25 * * *$ & $-38.76 * * *$ & $-49.53 * * *$ & $-0.885 * * *$ & $-1.215^{* * * *}$ & $-0.956 * * *$ & $-1.222 * * *$ \\
\hline $\mathrm{P}$ - Inc Drop - $E I^{7}$ & $-6.599 * * *$ & $-6.928 * * *$ & $-5.893 * * *$ & $-6.484 * * *$ & $-1.793 * * *$ & $-1.883^{* * * *}$ & $-1.601 * * *$ & $-1.762 * * *$ \\
\hline P - Exp Distress - $E I^{8}$ & $-15.51^{* * * *}$ & $-15.24 * * *$ & $-13.32 * * *$ & $-13.37 * * * *$ & $-1.250 * * *$ & $-1.229 * * *$ & $-1.074 * * *$ & $-1.078^{* * *}$ \\
\hline Joint $F$ & 21.51 & 21.03 & 19.31 & 19.24 & 21.51 & 21.03 & 19.31 & 19.24 \\
\hline
\end{tabular}

Note: The first four columns give estimates of parameter $\phi^{j}$ from $\mathrm{Eq}(6)$ for the eight insecurity measures. The right four columns show estimates in terms of standard deviation shocks for each measure and hence the parameters are comparable across measures. Model (1) uses no individual-specific controls, Model (2) uses basic economic and demographic controls, Model (3) employs life-event controls and Model (4) uses all available control variables. All equations are fitted by OLS and cluster robust heteroskedasticity consistent standard errors are used. Regressions are typically based on around 13,000 cross-sectional units and 50,000 observation/years. $* * *, * *$ and $*$ denote significance at $1 \%, 5 \%$ and $10 \%$ levels respectively.

Estimates of $\phi^{1}, \phi^{2}, \ldots, \phi^{j}$ from each model provide the central focus of the paper. When no time-varying controls are used (Model 1) all eight insecurity measures predict significantly diminished mental health, while when the standard set of controls is employed (model 2) six of the eight measures are still highly significant. When the life event controls are used we also see all eight measures having significant negative effects upon mental health, while if the full set of RHS variables is used all but the income reduction variable and the L\&C index are predictive. Thus over all estimates, the frequent rejection of the null in the anticipated direction indicates that mental health is sensitive to a wide variety of economic risks. Indeed the breadth of this finding suggests that the measures may all be reflecting the same (or very similar) underlying phenomena. It is worth noting that aside from being indicators of monetary risk exposure, the measures have little in common with each other. Once the financial aspect is removed, the experience of feeling insecure in one's job is rather unlike lacking access to emergency funds, or having a high probability of failing to meet basic expenses in the coming year. Because these variables are distinct aside from their 
characterization in terms of economic risk we conclude that this is likely to be the central mechanism underlying all these findings, rather than each being independently caused by the unique sets of non-monetary phenomena that accompany each specific risk. Thus we are implicitly invoking a "principle of parsimony" type argument in favor of a single coherent explanation, although it should be noted that while less likely, the alternative (where each result is due to separate non-monetary confounding factors) is not formally ruled out.

In addition to these models we can also consider an alternative case where all eight measures are simultaneously included in each equation. Such a specification makes sense if we wish to consider which risks are the most damaging while controlling for the presence of other forms of economic stress. The coefficients are omitted for the sake of brevity, although results from joint $F$ tests on the estimates are reported in the bottom row of Table 2. However, we note that across the four models the measures of job insecurity, probability of experiencing expenditure distress, and lacking access to emergency funds are the most predictive. As these variables are the primary drivers of diminished health, together we regard them as the three measures that best capture the latent concept of economic insecurity.

\section{Standard Deviation Shocks}

The results presented in the left panel of Table 2 show that many economic risks are harmful for health, however they do not allow us to consider whether or not some risks are more harmful than others. This is because in their current form the measures are distributed differently with varying units of measurement and hence each marginal effect requires a unique interpretation. In order to get around this problem we require some form of transformation of either the coefficient or the variable of interest. To account for the varying distributional properties of each measure the estimates on the RHS of Table 2 simulate the effect of a one standard deviation shock to each insecurity score. That is, the columns show the effect on mental health of such a shock in terms of units of the dependent variable defined by $\hat{\theta}^{j}=\hat{\sigma}_{E I^{j}} \times \widehat{\phi}^{j}$.

As Table 2 indicates, a shock of a single standard deviation to each measure has a fairly uniform effect on the $\mathrm{M}$ scores, generally congregating between -1.0 to -1.8 units per standard deviation. This is particularly the case for the significant measures and holds across all four models. Thus while there are slight differences in estimates produced using the alternative procedures, there is little indication that the effect sizes vary wildly from one risk concept to the next. Once some allowances for sampling variation are made, the reasonable degree of consistency across these results suggests that the mental health costs of economic insecurity are not sensitive acute factors specific to any particular hazard, measurement concept or econometric technique. Hence this consistency further bolsters the argument that the measures are acting via the same channel to affect mental health.

Assuming that these risk measures are capturing the same latent variable, it is useful to be able to make stylized comments on the general effect of this phenomenon. To accomplish this we calculate the mean impact of the standard deviations shock with the aim of producing a generic indicator of economic insecurity. Employing estimates from model (4) which contains the most extensive set of controls, we average over the significant estimates to produce a single representative summary statistic of -1.4 SF-36 MH units per standard deviation shock. We also consider the value of -1.0 as an approximation of the lower bound for the central cluster of estimates and -1.8 as an estimate for the upper bound.

In order to fully appreciate the public health consequences of economic insecurity it is necessary to consider how large a decline of these magnitudes actually is. If -1.4 units represents a very small change in SF-36 scores then it may be argued that even though 
insecurity does diminish health, the effect could be too small to warrant action. Conversely if this figure represents a large decline in wellbeing then economic risks may potentially be very harmful. Two methods are used to highlight the magnitude of this effect size. Initially the concept of a Minimum Clinically Important Difference (MCID) is considered, which represents the smallest change in health status that may be considered important by an individual. For the SF-36 and its subscales, estimates of MCID tend to range between 3 to 5 points (e.g. Walters and Brazier, 2003; Wyrwich et al., 2005) and hence two to four standard deviation shocks are required to have a minimally meaningful impact upon the mental health of any given individual.

Secondly the size of our stylized effect can be assessed using a close parallel between the SF36 mental health index and a similar highly correlated mental health variable, the K10 Kessler score (Kessler, Andrews \& Colpe, 2002). By matching percentiles of these distributions, discrete thresholds for SF-36 scores (which already exist for the K10) can be generated that classify individuals into groups ranging between "likely to be well" to "likely to be suffering a mild (moderate or severe) mental disorder". The representative figure of -1.4 units can be placed in context by considering the number of shocks to insecurity required to push an average individual to the thresholds of these categories. The average score over the Australian population is 74.24 in our sample, while the cutoffs for these disorders as implied by the K10 distribution are 59.11 (mild), 50.88 (moderate) and 42.06 (severe). These figures imply that an average individual requires approximately 10.8 standard deviation shocks to be classifiable as suffering from a mild disorder, a further 5.9 shocks to be reclassified as experiencing a moderate disorder, and another 6.3 to be severely unwell.

Thus we see that for the average individual the negative health effects of economic insecurity are unlikely to greatly affect their mental health status in a single specific year. Indeed several shocks are required to make a clinically important difference, and at least 10 are required to make an otherwise average person mentally unwell. However, this does not necessarily imply that the population-wide effects of economic insecurity are trivial. The impact of economic insecurity on the mental health of each individual in any one year has to be added to the cumulative impact of economic insecurity in previous years - e.g. the job insecurity experienced in 2015 is often experienced by people who were job insecure in 2014 and in previous years. As well, economic risks are widespread across the Australian population and are correlated in kind and in intensity. For example only $13 \%$ of the relevant subset of our sample agree that (i) their job is secure, and (ii) they are comfortable with their financial position, and (iii) that they could easily raise emergency funds if needed. Consequently it is likely both that most individuals face some sense of economic insecurity and experience slightly diminished mental wellbeing as a result, and that subsets of the population experience multiple types of economic insecurity which compound. In general, it is therefore necessary to consider the rate of exposure as well as the sensitivity to risk when evaluating the aggregate impact on population health.

\section{Discussion}

The paper has presented two novel contributions on the mental health effects of economic insecurity. The first relates to the robustness of negative health effects across different types of economic risk, the second relates to the degree of sensitivity of mental health to these risks. We consider some of the policy implications of these findings in turn.

Given the fact that such a diverse range of risks have been found to harm mental health, this suggests that the mutual economic component of these risks is likely to lie at the heart of the 
problem. This finding is rather general and implies that any risky situation that threatens the economic wellbeing of the individual will also damage their psychological health. Thus if policy makers are interested in protecting against the health consequences of economic insecurity they should not just consider hazards that have been shown to be harmful (such as the prospect of job loss) but any potential risk that may cause a substantial deterioration in economic wellbeing (see Hacker (2006) for an extensive discussion). Indeed factors that one may not immediately consider as potentially harmful such as the threat of loss via divorce, widowhood, unexpected expenses, or the withdrawal of governmental income support are also likely to generate negative effects. The lesson for policy makers here appears to be to cast the net widely when designing social safety nets.

Our second finding was that a standard deviation shock to our measures lowered an individual's SF-36 MH score by about -1.4 units on average, with an upper bound of around 1.0 and a lower bound of about -1.8 units. Although this constitutes a fairly limited effect, the implications for population health can be placed in context by considering what fraction of the Australian population lies within these bounds and the threshold for being regarded as suffering from a mental disorder. Using an adaptive kernel density estimator (Van Kerm, 2003) we observe that approximately $1.7 \%$ of our data lie 1.4 units or less above this cutoff, and hence a standard deviation shock to all individuals (occurring for example from a recession or large cut to social safety nets) would increase the morbidity rate of mental disorders by about this amount. If the true effect is as low as 1.0 the increase in morbidity is $1.3 \%$, while an effect size of 1.8 units per standard deviation shock would increase mental disorders by about $2.3 \%$. These percentages are taken relative to the total population; if we consider the change relative to baseline morbidity rates then a population wide shock of a single standard deviation would increase the rates by between $10-18 \%$. We therefore summarize by noting that the effects of economic insecurity on any given individual are normally quite small, but can have non-trivial epidemiological effects due a wide degree of exposure.

Finally there are several limitations to the study that should be emphasized. These mostly relate to the econometric models we employ which can be susceptible to endogeneity biases due to misspecification, omitted variables, missing observations or reverse causality. Thus it is possible that the presence of other phenomena (such as a decline in mental health affecting an individual's sense of security) could be adversely affecting our results. Similar issues arise due to imperfections in measuring economic insecurity. If a variable of interest is measured with error the corresponding parameter estimates will be biased towards zero (Griliches, 1984). In our case this would result in an understatement of the effects of economic insecurity upon health and potentially account for the small effect sizes we uncover.

\section{Conclusion}

This paper has investigated the extent to which economic insecurity causes deterioration in the mental health of the Australian public. A wide variety of economic insecurity measures were developed and examined as determinants of mental health as measured by the SF-36 summary index. Coefficient estimates on a number of insecurity estimates were highly significant, robust and of the expected sign. Results indicate that negative health effects can be attributed to changes in financial dissatisfaction, feelings of job insecurity, the inability to produce emergency funds, the risk of downward income mobility and the probability of failing to meet standard household expenses in the future. Our preferred models indicate that a standard deviation shock to the measures reduces the SF-36 Mental Summary by around 1.0-1.8 points. These shifts are of a plausible magnitude. Two to four shocks are required to 
have a minimal clinically important effect on mental health, and around 11 shocks are required to move an average individual to the threshold of a minor psychological disorder.

The results represent a number of new contributions to the literature. First, ours is one of a limited number of papers to consider endogeneity issues when modeling economic risks and mental health. Second as we employed multiple measures of insecurity we were able to ascertain whether any ill effects were specific to particular risks, or if diminished psychological health is likely to be an effect of any generic economic risk. The consistency in statistical significance and the reasonable degree of similarity of these estimates shows that there are mental health consequences for a wide variety of objective and perceived economic risks, which reinforces the hypothesis that the common element of prospective economic loss is likely to be harmful for mental health.

Last, we examined the public health consequences of risk exposure by simulating the effects of a standard deviation shock to all individuals. Although in a given year, the average individual can deal with a shock of this magnitude without serious consequences, at the population level the morbidity rates of mental disorders would increase by about $10-18 \%$. Since these numbers are substantial when compared to baseline rates we conclude that when aggregated, concerns over economic risks have the potential for significant negative impacts on mental wellbeing.

\section{References}

Bandyopadhyay, S., \& Cowell, F. (2007). Modelling vulnerability in the UK, LSE STICERD Research Paper 89.

Barnes, M., \& Smith, T. (2009). Tobacco Use as Response to Economic Insecurity: Evidence from the National Longitudinal Survey of Youth, The B.E. Journal of Economic Analysis \& Policy, 9, 1.

Blakely, T., Collings, S., \& Atkinson, J. (2003). Unemployment and suicide. Evidence for a causal association?, Journal of Epidemiology and Community Health, 57, 594-600.

Bossert, W., \& D'Ambrosio, C. (2013). Measuring Economic Insecurity, International Economic Review, 54, 1017-1030.

Böckerman, P., Ilmakunnas, P., \& Johhansson, E. (2011). Job security and employee wellbeing: Evidence from matched survey and register data, Labour Economics, 18, 547-554.

Bowling, A. (1997). Measuring Health: A Review of Quality of Life Measurement Scales, London: Open University Press.

Bucks, B. (2011). Economic Vulnerability in the United States: Measurement and Trends, Paper Prepared for the IARIW-OECD Conference on Economic Insecurity, Paris, France.

Calvo, C., \& Dercon, S. (2005). Measuring individual vulnerability, Economics Series Working Papers 229, University of Oxford, Department of Economics.

Cannuscio, C., Alley, D., Pagán, J., Soldo, E., Krasny, S., Shardell, M., Asch, D., \& Lipman, T. (2012). Housing Strain, Mortgage Foreclosure, and Health, Nursing Outlook, 60, 134-142.

Caroli, E., \& Godard, M. (2013). Does Job Insecurity Deteriorate Health? A Causal Approach for Europe, PSE Working Papers hal-00784777, HAL. 
Cheng, Y., Chen, C.W., Chen, C.J., \& Chiang, T. (2005). Job insecurity and its association with health among employees in the Taiwanese general population, Social Science \& Medicine, 61, 41-52.

De Witte, H. (1999). Job insecurity and psychological well-being: Review of the literature and exploration of some unresolved issues, European Journal of Work and Organizational Psychology, 8, 155-177.

Dominitz, J., \& Manski, C. (1997). Perceptions of Economic Insecurity, Public Opinion Quarterly 61, 2, 261-87.

Donaldson, D., \& Weymark, J. (1980). A Single-Parameter Generalization of the Gini Indices of Inequality, Journal of Economic Theory, 22, 67-86.

Ferrie, J., Shipley, M., Marmot, M., Stansfeld, S., \& Davey Smith, G. (1998). The health effects of major organisational change and job insecurity, Social Science \& Medicine, 46, $243-254$.

Fryer, D., \& Fagan, R. (2003). Toward a critical community psychological perspective on unemployment and mental health research, American Journal of Community Psychology, 32, 89-96.

Gelman, A., \& Loken, E. (2013). The garden of forking paths: Why multiple comparisons can be a problem, even when there is no "fishing expedition" or "p-hacking" and the research hypothesis was posited ahead of time, Department of Statistics, Columbia University, New York, NY.

Green, F. (2011). Unpacking the misery multiplier: How employability modifies the impacts of unemployment and job insecurity on life satisfaction and mental health, Journal of Health Economics, 30, 265-276.

Griliches, Z. (1984). "Data problems in econometrics" NBER Technical Working Papers 0039, National Bureau of Economic Research, Inc.

Hacker, J. (2006). The great risk shift: The assault on American jobs, families, health care, and retirement and how you can fight back, Oxford University Press, USA.

Hacker, J., Huber, G., Rehm, P., Schlesinger, M., \& Valletta, R. (2010). Economic Security at Risk: Findings from the Economic Security Index, Rockefeller Foundation, Yale University.

Hausman, J. (1978). Specification Tests in Econometrics, Econometrica, 46, 6, 1251-1271.

Hintikka, J., Saarinen, P., \& Viinamaki, H. (1999). Suicide mortality in Finland during an economic cycle 1985-1995, Scandinavian Journal of Public Health, 27, 85-88.

Kahneman, D., \& Tversky, A. (1979). Prospect Theory: An Analysis of Decision under Risk, Econometrica, 47, 2, 263-291.

Kalleberg, A. (2009). Precarious Work, Insecure Workers: Employment Relations in Transition, American Sociological Review, 74, 1-22.

Kessler, R., Andrews, G., \& Colpe, L. (2002). Short screening scales to monitor population prevalences and trends in non-specific psychological distress, Psychological Medicine, 32, 959-956. 
Kessler, R., Turner, J., \& House, J. (1989). Unemployment, reemployment, and emotional functioning in a community sample, American Sociological Review, 54, 648-657.

Landsbergis, P., Grzywacz, J., \& LaMontagne, A. (2014). Work organisation, job insecurity and occupational health disparities, American journal of industrial medicine, 57, 1-21.

Larson, J., Wilson, S., \& Beley, R. (1994). The Impact of Job Insecurity on Marital and Family Relationships, Family Relations, 43, 138-143.

Laszlo, K., Pikhart, H., Kopp, M., Bobak, M., Pajak, A., \& Malyutina, S. (2010). Job insecurity and health: a study of 16 European countries, Social Science \& Medicine, 70, 867874.

Lim, V. (1996). Job insecurity and its outcomes: Moderating effects of work-based and nonwork-based social support, Human Relations, 2, 171-194.

Luechinger, S., Meieer, S., \& Stutzer, A. (2009). Why Does Unemployment Hurt the Employed? Evidence from the Life Satisfaction Gap between the Public and the Private Sector, Journal of Human Resources, 45, 4, 998-1045.

McDonough, P. (2000). Job insecurity and health, International Journal of Health Services, 30, 453-476.

Meltzer, H., Bebbington, P., Brugha, T., Jenkins, R., McManus, S., \& Stansfeld, S. (2009). Job insecurity, socio-economic circumstances and depression, Psychological Medicine, 40, 8, $1401-7$.

Mirowsky, J., \& Ross, C. (1989). Social Causes of Psychological Distress, Aldine De Gruyter, New York.

Nichols, A., \& Rehm, P. (2014). Trends in Income Inequality, Intertemporal Variability, and Mobility Risk in Thirty Countries, Review of Income and Wealth, S60, 98-116.

Offer, A., Pechey, R., \& Ulijasazek, S. (2010). Obesity under affluence varies by welfare regimes: The effect of fast food, insecurity, and inequality, Economics and Human Biology, 8, 3, 297-208.

Osberg, L. (1998). Economic Insecurity, Discussion Papers 0088, University of New South Wales, Social Policy Research Centre.

Osberg, L., \& Sharpe, A. (2002). An Index of Economic Well-Being for Selected OECD Countries, Review of Income and Wealth, 48, 3, 291-316.

Raviv, A., Keinan, G., Abazon, Y., \& Raviv, A. (1990). Moving as a stressful life event for adolescents, Journal of Community Psychology, 18, 130-140.

Rohde, N., Tang, K., \& Rao, D. (2014). Distributional Characteristics of Income Insecurity in the US, Germany and Britain, Review of Income and Wealth, S60, 159-176.

Scheve, K., \& Slaughter, M. (2004). Economic insecurity and the globalization of production, American Journal of Political Science 48, 4, 662-674.

Sharpe, A., \& Osberg, L. (2009). New Estimates of the Index of Economic Well-being for Selected OECD Countries 1981 - 2007, CSLS Research Reports 2009-11, Centre for the Study of Living Standards. 
Slopen, N., Glynn, R., Buring, J., Lewis, T., Williams, D., \& Albert, M. (2012). Job strain, job insecurity, and incident cardiovascular disease in the Women's Health Study: results from a 10-year prospective study PloS One 7:e40512.

Smith, T., Stoddard, C., \& Barnes, M. (2009). Why the poor get fat: Weight gain and economic insecurity, Forum for Health Economics \& Policy, 12, 5.

Standing, G. (1997). Globalisation, labour flexibility and insecurity: The era of market regulation, European Journal of Industrial Relations, 3, 1, 7-38.

Stiglitz, J., Sen, A., \& Fitoussi, J. (2009). Report by the commission on the measurement of economic performance and social progress. Paris. http://www.stiglitzsen-

fitoussi.fr/en/index.htm.

Stuckler, D., Basu, S., Suhrcke, M., Coutts, A., \& McKee, M. (2009). The public health effect of economic crises and alternative policy responses in Europe: an empirical analysis, The Lancet, 374, 315-323.

Sverke, M., Hellgren, J., \& Näswall, K. (2002). No security: A meta-analysis and review of job insecurity and its consequences, Journal of Occupational Health Psychology, 7, 3, 242 264.

Tsutsumi, A., Kayaba, K., Theorell, T., \& Siegrist, J. (2001). Association between job stress and depression among Japanese employees threatened by job loss in a comparison between two complementary job-stress models, Scandinavian Journal of Work, Environment and Health, 27, 2, 146-153.

United Nations Universal Declaration of Human Rights (adopted 10 December 1948 UNGA Res 217 A(III) (UDHR) article 5.

Van Kerm, P. (2003). Adaptive kernel density estimation, Stata Journal, 3, 148-156.

Walters, S., \& Brazier, J. (2003). What is the relationship between the minimally important difference and health state utility values? The case of the SF-6D, Health and Quality of Life Outcomes, $1,4$.

Western, B., Bloom, D., Sosnaud, B., \& Tach, L. (2012). Economic insecurity and social stratification, Annual Review of Sociology, 38, 341-359.

Wyrwich, K., Tierney, W., Babu, A., Kroenke, K., \& Wolinsky, F. (2005). A Comparison of Clinically Important Differences in Health-Related Quality of Life for Patients with Chronic Lung Disease, Asthma, or Heart Disease, Health Services Research, 40, 577-592.

\section{Appendix A1}

Table 3 presents analogous estimates to those given in Table 2 where missing values are accounted for using multiple imputation methods. The results are very similar to those presented above and hence we conclude that our findings are not greatly affected by missing values for the dependant variable.

Table 3:Estimated Impacts of Economic Insecurity on SF-36 Mental Health - Imputed Values

\begin{tabular}{|c|c|c|c|c|c|c|c|c|}
\hline Variable & \multicolumn{4}{|c|}{ Unit Changes $(\hat{\phi})$} & \multicolumn{4}{|c|}{ Std Dev Shocks $(\hat{\theta})$} \\
\hline & (1) & (2) & (3) & (4) & (1) & (2) & (3) & (4) \\
\hline Job Insecurity - $E I^{1}$ & $-0.754 * * *$ & $-0.734 * * *$ & $-0.767 * * *$ & -0.755 *** & $-1.280 * * *$ & $-1.247 * * *$ & $-1.303^{* * * *}$ & $\mid-1.283^{* * * *}$ \\
\hline Financial Diss $-E I^{2}$ & $-0.855^{* * * *}$ & $-0.825 * * *$ & $-0.845 * * *$ & $-0.827 * * *$ & -1.966 **** & $-1.897 * * *$ & $-1.944 * * *$ & $-1.901 * * *$ \\
\hline Emerg Funds - $E I^{3}$ & $-1.303^{* * *}$ & $-1.231^{* * * *}$ & $-1.269 * * *$ & $-1.229 * * *$ & $-1.383 * * *$ & $-1.307 * * *$ & -1.347 *** & $-1.305 * * *$ \\
\hline
\end{tabular}




\section{ACCEPTED MANUSCRIPT}

\begin{tabular}{|c|c|c|c|c|c|c|c|c|}
\hline Income Drop - $E I^{4}$ & $-0.670 * * *$ & -0.215 & $-0.570 * * *$ & -0.160 & $-0.182 * * *$ & -0.058 & -0.155 & $-0.043 * * *$ \\
\hline L\&C Index $-E I^{5}$ & $-1.13 \mathrm{E}-06 * * *$ & $4.97 \mathrm{E}-07$ & $-9.00 \mathrm{E}-07 * * * *$ & $6.20 \mathrm{E}-07$ & $-0.108 * * *$ & $0.048 * * *$ & $-0.086 * * *$ & $0.059 * * *$ \\
\hline P - Unemploy - $E I^{6}$ & $-35.934 * * *$ & $-49.211^{* * * *}$ & $-38.952 * * *$ & $-49.611^{* * * *}$ & -0.886 **** & $-1.214 * * *$ & $-0.961 * * *$ & $-1.224 * * *$ \\
\hline $\mathrm{P}$ - Inc Drop - $E I^{7}$ & $-6.598 * * *$ & $-6.884 * * *$ & $-5.909 * * *$ & $-6.456 * * *$ & $-1.793 * * *$ & $-1.870 * * *$ & $-1.606^{* * * *}$ & $-1.754 * * *$ \\
\hline $\mathrm{P}$ - Exp Distress $-E I^{8}$ & $-15.676 * * *$ & $-15.416 * * *$ & $-13.645^{* * * *}$ & $-13.696^{* * *}$ & $-1.264 * * *$ & $-1.243 * *$ & $-1.100^{* * *}$ & $\mid-1.104 * * *$ \\
\hline
\end{tabular}

Note: The estimates presented here correspond to those given in Table 2 however we have used multiple imputation methods to account for missing values in the dependent variable. 


\section{The Effect of Economic Insecurity on Mental Health: Recent Evidence from Australian Panel Data}

August 20, 2015

Key Words: Economic Insecurity, Mental Health, Panel Data.

\section{Highlights}

- We estimate the impact of economic insecurity on mental health.

- Significant negative impacts are found for a diverse range of economic risks.

- This suggests the common element of monetary risk is at least partially responsible.

- Empirical associations do not appear biased by unobservable confounding factors.

- Simulations assess the epidemiological consequences of economic insecurity. 


\section{Accepted Manuscript}

The Effect of Economic Insecurity on Mental Health: Recent Evidence from Australian Panel Data

Nicholas Rohde, K.K. Tang, Lars Osberg, Prasada Rao

PII: S0277-9536(15)30274-4

DOI: $\quad$ 10.1016/j.socscimed.2015.12.014

Reference: SSM 10415

To appear in: Social Science \& Medicine

Received Date: 3 June 2015

Revised Date: 4 December 2015

Accepted Date: 10 December 2015

Please cite this article as: Rohde, N., Tang, K., Osberg, L., Rao, P., The Effect of Economic Insecurity on Mental Health: Recent Evidence from Australian Panel Data, Social Science \& Medicine (2016), doi: 10.1016/j.socscimed.2015.12.014.

This is a PDF file of an unedited manuscript that has been accepted for publication. As a service to our customers we are providing this early version of the manuscript. The manuscript will undergo copyediting, typesetting, and review of the resulting proof before it is published in its final form. Please note that during the production process errors may be discovered which could affect the content, and all legal disclaimers that apply to the journal pertain. 